\title{
Fluency in Parkinson's disease: disease duration, cognitive status and age
}

\author{
Fluência na doença de Parkinson: tempo da doença, status cognitivo e idade \\ Natalia Casagrande Brabo, Thais Soares C. Minett, Karin Zazo Ortiz
}

\begin{abstract}
The objective of this study was to determine the frequency of occurrence and to characterize the typology of dysfluencies in individuals with Parkinson's disease (PD), including the variables age, gender, schooling, disease duration, score on the Hoehn and Yahr scale and cognitive status (score on Mini-Mental State Examination). A cross-sectional study of a sample comprising 60 adults matched for gender, age and schooling was conducted. Group I comprised 30 adults with idiopathic PD, and Group II comprised 30 healthy adults. For assessment of fluency of speech, subjects were asked to utter a narrative based on a sequence of drawings and a transcription of 200 fluent syllables was performed to identify speech dysfluencies. PD patients exhibited a higher overall number of dysfluencies in speech with a large number of atypical dysfluencies. Additionally, results showed an influence of the variables cognitive status, disease duration and age on occurrence of dysfluencies.
\end{abstract}

Keywords: Parkinson's disease, cognition, speech.

\section{RESUMO}

O objetivo deste estudo foi avaliar a frequência de ocorrência e caracterizar a tipologia das disfluências em indivíduos com doença de Parkison (DP), controlando-se as variáveis, idade, sexo, escolaridade, tempo de doença, escore na escala de Hoehn e Yahr e status cognitivo (escore no Exame do Minimental). Realizamos um estudo transversal com amostra composta por 60 adultos pareados por sexo, idade e escolaridade. 0 grupo I foi formado por 30 adultos com DP idiopática, e o grupo II por 30 adultos sadios. Para a avaliação da fluência da fala foi solicitada a emissão de uma narrativa a partir de uma sequência de figuras e realizada a trascrição de 200 sílabas para verificação das disfluências de fala. Os pacientes com DP apresentaram um número maior de disfluências na fala com um grande número de disfluências atípicas e, adicionalmente, observamos que houve interferência das variáveis status cognitivo, tempo de doença e idade na ocorrência das disfluências.

Palavras-chave: doença de Parkinson, cognição, fala.

Parkinson's disease (PD) is characterized by a degeneration of neurons in the substantia nigra of the mesencephalon, leading to a fall in dopamine production. Dysfunction in the basal ganglia circuits is a determining factor in the physiopathology of the classic signs, and hypokinetic dysarthria is commonly related to PD, with one of its symptoms being impaired speech fluency ${ }^{1}$.

Neurogenic stuttering is an acquired disorder of speech fluency secondary to a neuropathology identified in individuals with no history of fluency problems prior to the occurrence of the neurological disease ${ }^{2}$. Some studies have reported that basal ganglia circuits play a key role in the mechanisms of stuttering ${ }^{3,4}$. On the basis this relationship, several studies were carried out examining the speech of subjects with PD in an effort to characterize these fluency disorders ${ }^{5,6,7,8}$. The dysfluencies described in individuals with PD were: repetition and prolongation of first and last syllables of words, sound repetition, audible and inaudible blocks, revisions and interjections ${ }^{4,5,7,8}$. Episodes of palilalia were also observed, described as involuntary repetitions of syllable, words or sentences ${ }^{9}$, a feature which appears much more frequently than normally seen in developmental stuttering ${ }^{10}$. Akin to any motor disorder however, these may have variable characteristics regarding aspects of motor programming and execution of articulatory gestures and may also be influenced by some sociodemographic variables such as age $^{11}$ and schooling ${ }^{12}$.

Therefore, the objective of this study was to determine the frequency of occurrence and to characterize the typology of dysfluencies, controlling for the variables age, gender, 
schooling, disease duration, score on the Hoehn and Yahr scale and cognitive status (score on Mini-Mental State Examination (MMSE)) in individuals with PD.

\section{METHOD}

This study was approved by the Research Ethics Committee of the Universidade Federal de São Paulo (protocol number 0843\09). All participants signed a free and informed consent form.

\section{Casuistic}

A cross-sectional study was conducted in a sample of 60 adults matched for gender, age and schooling: 30 adult patients diagnosed with idiopathic PD attended at the Sector for Motor Disorders of the Neurology Department of the Universidade Federal de São Paulo, and 30 healthy adults (control group) that were companions or family members of the patients assessed.

The general inclusion criteria for both groups were as follows: age greater than or equal to 50 years; schooling greater than or equal to 4 years; absence of personal or familial history of developmental or psychogenic stuttering; absence of history of stroke or previous traumatic brain injury; absence of alcoholism or use of illegal drugs; visual or hearing impairments which could affect performance on the tasks given; normal performance on the MMSE for educational level, according to the standards established for the Brazilian population $^{13}$, to exclude subjects with dementia from the sample and ensure that impairments in cognitive aspects did not interfere with the specific assessment.

The patients participating in the study were diagnosed with PD, had not undergone neurosurgery, were at stages 2, 2.5 or 3 on the Hoehn and Yahr ${ }^{14}$ scale, and in use of medication for PD.

The control group consisted of healthy adult volunteers who had less than $3 \%$ atypical dysfluencies or less than $10 \%$ typical fluencies in speech. These are cut off values according the criteria of the Stuttering Severity Instrument (SSI-3) $)^{15}$.

\section{Procedures}

All patients were followed by neurologists who conducted both anamnesis and physical examinations.

For the assessment of fluency of speech and data collection for the sample, the study participants were asked to produce a narrative based on a sequence of drawings constituting the ("The dog story") ${ }^{16}$. The following task was elicited from subjects: "Can you see this card. It is made up of these seven drawings (examiner points to the drawings in order). I want you to tell me the story you see in these drawings. You can look at them for as long as you need before starting." The test commenced from the point the individual started telling the story and finished when the individual indicated they had nothing further to say.

In addition to the narrative, subjects were also asked to describe a typical day in order to create a sufficient speech sample for subsequent analysis.The instruction was "Please, tell me everything that you normally do during the day".

All patients were at the on phase of the medication during the assessment.

Data collection was carried out on an individual basis. The discourse produced was recorded using a digital camera SONY Cyber - shot 6.0 mega pixels) and later transcribed.

\section{Analysis of results}

The criteria adopted for sample collection and analysis of speech were those proposed in the Speech Fluency Assessment Protocol ${ }^{17}$, applied to classify typology of breaks into typical or atypical dysfluencies, based on transcription of 200 expressed syllables. The definitions of the dysfluencies proposed by the author are outlined below.

Typical dysfluencies: hesitations; interjections; revisions; unfinished words; repetition of words, segments and sentences.

Atypical dysfluencies: repetitions of syllables; repetition of sounds; prolongation; blocking; pauses (over two seconds) and intrusions of sounds or segments.

Episodes of palilalia were also registered, characterized by the presence of repetitions of syllables (over four times) and words (over three times), with or without acceleration of speech rate. Palilalia episodes were classified as atypical dysfluency, since these are expected symptoms in PD and do not figure in the speech of subjects without neurological disorders.

For analysis of the speech dysfluencies exhibited by the PD and control groups, the absolute number of each dysfluency was computed for each individual, stratified into typical and atypical dysfluencies. Subsequently, the number of typical, atypical and total (typical plus atypical) dysfluencies exhibited by both groups was calculated and compared.

Speech rate was measured in words per minute and syllables per minute. Means were calculated by dividing total number of words or syllables by total sample time. The study analysis entailed comparing the mean speech rates for the PD and Control groups

\section{Statistical analysis}

Categorical data were compared using the Chi-squared $\left(\chi^{2}\right)$ test (without Yates comparison) with application of Fisher's exact test when Cochran's restrictions were present.

Student's $t$-test for independent samples was employed to compare means for continuous data, whereas Student's $t$-test for dependent sample was applied for paired samples.

Multiple linear regression analysis was performed to check which variables had the greatest influence on typical 
and atypical dysfluencies (dependent variables). Age, gender, schooling, disease duration, score on the Hoehn and Yahr scale and score on the MMSE were preselected as independent variables. The step-wise forward method was used to select independent variables for inclusion in the final model.

There was no missing data.

A probability (p) of less than 0.05 was considered statistically significant and all tests were two-tailed. Differences among means were calculated for a ninety-five percent confidence interval $(95 \% \mathrm{CI})$. All statistical analyses were carried out using the software SPSS (Statistical Package for the Social Science) version 11.5.1 for Windows.

\section{RESULTS}

Forty patients with PD attended at the Sector for Motor Disorders of the Department of Neurology of the Universidade Federal de São Paulo were scheduled for phonoaudiological assessments between September 2009 and May 2010. Of this total, 10 were not included in the sample because they did not attend the scheduled session. Thus, a total of 30 patients followed the protocol, in addition to 30 controls. The data from these 60 subjects were considered in the subsequent analyses.

\section{General characteristics}

The age of subjects in the sample ranged from 50 to 75 years, with a mean age $62.3 \pm 7.0$ years, and in terms of gender, $82 \%$ were men. The general characteristics are shown in Table 1.

There were no statistically significant differences between the Control group (CG) and the Parkinson's disease group (PDG) for age $(62.4 \pm 6.9$ versus $62.2 \pm 7.1$ years; $\mathrm{t}(58)=0.13 ; 95 \% \mathrm{CI}=-3.4$ to $3.9 ; \mathrm{p}=0.898)$, schooling $(8.7 \pm 4.2$ versus $8.4 \pm 4.2$ years; $t(58)=0.21 ; 95 \% \mathrm{CI}=-2.0$ to $2.4 ; \mathrm{p}=0.832)$. Score on the MMSE $(28.5 \pm 1.2$ versus $28.4 \pm 1.4$; $\mathrm{t}(58)=0.29$; $95 \% \mathrm{CI}=-0.6$ to $0.8 ; \mathrm{p}=0.770)$ or gender $(83 \%$ versus $80 \%$ men; $\left.\chi^{2}(1)=0.11 ; p=0.739\right)$.

\section{Clinical characteristics of PD patients}

Disease duration ranged from 2 to 20 years (mean=9.9, $\mathrm{SD}=4.4$ ), $20 \%$ of patients had a score of 2 on the Hoehn

Table 1. Individual data of groups studied.

\begin{tabular}{|c|c|c|c|c|c|c|c|c|c|}
\hline & & & & & & & & CG & \\
\hline & Age & Schooling & MEEM & Drugs & $\mathrm{DD}$ & $H \& Y$ & Age & Schooling & MEEM \\
\hline 1 & 66 & 12 & 30 & C & 13 & 3 & 50 & 8 & 27 \\
\hline 2 & 58 & 5 & 27 & C & 8 & 3 & 52 & 10 & 29 \\
\hline 3 & 73 & 8 & 27 & S & 12 & 3 & 64 & 15 & 30 \\
\hline 4 & 66 & 4 & 27 & S & 2 & 2.5 & 55 & 4 & 29 \\
\hline 5 & 66 & 5 & 27 & C & 12 & 3 & 75 & 15 & 29 \\
\hline 6 & 58 & 4 & 26 & C & 15 & 2 & 75 & 8 & 30 \\
\hline 7 & 59 & 4 & 27 & C & 11 & 3 & 63 & 15 & 29 \\
\hline 8 & 59 & 5 & 28 & C & 4 & 2 & 69 & 4 & 28 \\
\hline 9 & 64 & 11 & 30 & C & 10 & 2 & 70 & 4 & 28 \\
\hline 10 & 58 & 4 & 25 & C & 9 & 2.5 & 63 & 4 & 26 \\
\hline 11 & 66 & 8 & 30 & S & 12 & 2.5 & 55 & 11 & 30 \\
\hline 12 & 68 & 15 & 29 & C & 4 & 2 & 69 & 5 & 28 \\
\hline 13 & 65 & 15 & 30 & C & 2 & 2 & 62 & 15 & 29 \\
\hline 14 & 52 & 4 & 27 & C & 8 & 2.5 & 52 & 11 & 29 \\
\hline 15 & 75 & 12 & 30 & C & 11 & 3 & 65 & 15 & 30 \\
\hline 16 & 73 & 4 & 29 & C & 10 & 2.5 & 67 & 4 & 25 \\
\hline 17 & 60 & 15 & 29 & C & 10 & 2.5 & 67 & 4 & 26 \\
\hline 18 & 55 & 15 & 29 & C & 10 & 2 & 67 & 4 & 29 \\
\hline 19 & 68 & 15 & 29 & C & 6 & 2.5 & 69 & 5 & 29 \\
\hline 20 & 65 & 4 & 28 & $S$ & 4 & 2.5 & 60 & 8 & 29 \\
\hline 21 & 52 & 10 & 30 & C & 12 & 3 & 56 & 8 & 28 \\
\hline 22 & 66 & 15 & 30 & C & 10 & 2.5 & 60 & 8 & 30 \\
\hline 23 & 56 & 5 & 28 & C & 6 & 2.5 & 60 & 4 & 27 \\
\hline 24 & 68 & 8 & 29 & $S$ & 8 & 2.5 & 54 & 15 & 29 \\
\hline 25 & 70 & 11 & 30 & C & 20 & 3 & 55 & 8 & 29 \\
\hline 26 & 50 & 8 & 28 & C & 14 & 3 & 60 & 8 & 29 \\
\hline 27 & 53 & 4 & 27 & C & 17 & 3 & 72 & 12 & 29 \\
\hline 28 & 50 & 11 & 29 & $S$ & 18 & 3 & 68 & 4 & 28 \\
\hline 29 & 69 & 4 & 28 & C & 8 & 3 & 60 & 12 & 29 \\
\hline 30 & 58 & 8 & 29 & C & 10 & 3 & 59 & 12 & 28 \\
\hline
\end{tabular}

PDG: Parkinson's Disease Group; CG: Control Group; DD: Disease Duration; C: Combined Medication; S: Single Medication. 
Table 2. Statistical data of groups studied concerning speech fluency.

\begin{tabular}{|c|c|c|c|c|c|c|c|c|c|c|}
\hline & \multicolumn{5}{|c|}{$\mathrm{CG}$} & \multicolumn{5}{|c|}{ PDG } \\
\hline & Mean & SD & Minimun & Maximun & Median & Mean & SD & Minimun & Maximun & Median \\
\hline Hesitations & 0.73 & 1.48 & 0 & 7 & 0 & 0.37 & 1.13 & 0 & 6 & 0 \\
\hline Intejections & 2.3 & 2.17 & 0 & 9 & 2 & 1.97 & 2.17 & 0 & 9 & 1.5 \\
\hline Revisions & 0.53 & 0.78 & 0 & 3 & 0 & 0.43 & 0.77 & 0 & 3 & 0 \\
\hline Unfinished words & 0.17 & 0.46 & 0 & 2 & 0 & 0.1 & 0.31 & 0 & 1 & 0 \\
\hline Repetition of words & 0.8 & 1.19 & 0 & 5 & 0 & 0.9 & 1.24 & 0 & 5 & 0 \\
\hline Repetition of segments & 0.17 & 0.46 & 0 & 2 & 0 & 0.57 & 1.28 & 0 & 5 & 0 \\
\hline Repetition of sentences & 0.07 & 0.25 & 0 & 1 & 0 & 0 & 0 & 0 & 0 & 0 \\
\hline Repetition of syllables & 0.03 & 0.18 & 0 & 1 & 0 & 0.2 & 0.48 & 0 & 2 & 0 \\
\hline Repetition of sounds & 0 & 0 & 0 & 0 & 0 & 0.07 & 0.37 & 0 & 2 & 0 \\
\hline Prolongations & 0 & 0 & 0 & 0 & 0 & 0.23 & 0.57 & 0 & 2 & 0 \\
\hline Blocking & 0 & 0 & 0 & 0 & 0 & 0.5 & 0.97 & 0 & 3 & 0 \\
\hline Intrusions of sounds & 0 & 0 & 0 & 0 & 0 & 0.1 & 0.31 & 0 & 1 & 0 \\
\hline Pauses & 0 & 0 & 0 & 0 & 0 & 0.93 & 1.66 & 0 & 8 & 0 \\
\hline Palilalia- words & 0 & 0 & 0 & 0 & 0 & 0.97 & 2.34 & 0 & 8 & 0 \\
\hline Palilalia- syllabes & 0 & 0 & 0 & 0 & 0 & 1.53 & 3.03 & 0 & 11 & 0 \\
\hline Total of syllabes & 207.97 & 5.26 & 201 & 223 & 207 & 214.53 & 15.28 & 191 & 250 & 209.5 \\
\hline Total of words & 107.57 & 7.29 & 94 & 121 & 108 & 112.6 & 15.43 & 89 & 155 & 110.5 \\
\hline Speech rate: syl/min & 247.67 & 47.02 & 168.5 & 342.9 & 251.2 & 216 & 57.79 & 116 & 363.6 & 214.9 \\
\hline Spech rate: words/min & 129.44 & 27.96 & 83.83 & 183.42 & 129.4 & 112.44 & 27.12 & 62.97 & 183.63 & 111.6 \\
\hline
\end{tabular}

PD: Parkinson's Disease Group; CG: Control Group; SD: Standard Deviation.

and Yahr scale, 37\% scored 2.5 and the remainder scored 3. A total of $90 \%$ of the patients were in use of Levodopa, 37\% Amantadine, 10\% Selegiline, 60\% Pramipexole and 13\% Biperidene. Of the 30 patients in the sample, 24 (80\%) were in use of combined medications whereas 6 (20\%) used a single medication. Of the single users, five used levodopa and one pramipexole.

\section{Assessment of speech fluency}

None of the subjects from the CG presented subjective stuttering complaints whereas $63 \%$ of patients from the PDG presented the complaint. This difference reached significance: $\chi^{2}(1)=27.8 ; \mathrm{p}<0.001$.

The total number of dysfluencies found in the CG was significantly lower than the number in the PDG (4.8 \pm 2.6 versus $8.9 \pm 6.7 ; \mathrm{t}(58)=-3.12 ; 95 \% \mathrm{CI}=-6.7$ to $1.4 ; \mathrm{p}=0.003)$, although this difference was attributed to the number of atypical $(0.03 \pm 0.18$ versus $4.53 \pm 5.71 ; \quad t(58)=-4.31 ; 95 \% \mathrm{CI}=-6.59$ to $-2.41 ; \mathrm{p}<0.001)$ and not to typical $(4.6 \pm 2.6$ versus $4.3 \pm 3.6$; $\mathrm{t}(58)=0.53 ; 95 \% \mathrm{CI}=-1.2$ to $2.1 ; \mathrm{p}=0.598)$ dysfluencies.

Of the transcription of all of the syllables uttered (200 syllables uttered, free of breaks, plus dysfluent syllables), the CG uttered an average of $7.97 \pm 5.25$ extra syllables versus $14.53 \pm 15.28$ in the PDG. This difference reached statistical significance: $t(58)=-2.23 ; 95 \% \mathrm{CI}=-12.74$ to $-0.66 ; \mathrm{p}=0.030$. However, the total of words expressed did not differ significantly between groups (107.6 \pm 7.3 versus 112.6 \pm 15.4 ; $\mathrm{t}(58)=-1.61 ; 95 \% \mathrm{CI}=-11.27$ to $1.20 ; \mathrm{p}=0.112$ ).

Table 2 shows the data of groups studied.

\section{Speech rate}

Concerning speech rate, measured by syllables or words per minute, the CG was significantly faster than the PDG:

- $247.7 \pm 47.0$ versus $216.0 \pm 57.8$; $\mathrm{t}(58)=2.33$; $95 \% \mathrm{CI}=4.4$ to 58.9 ; $\mathrm{p}=0.023$

- $129.4 \pm 28.0$ versus $112.4 \pm 27.1$; $\mathrm{t}(58)=2.39 ; 95 \% \mathrm{CI}=2.8$ to 31.2 ; $\mathrm{p}=0.020$

Influence of disease duration, cognitive status and age on speech fluency

Multiple linear regression analysis was performed to check which variables had the greatest influence on typical dysfluencies (dependent variable). Age, gender, schooling, disease duration, score on the Hoehn and Yahr scale and score on the MMSE were preselected as independent variables. The stepwise forward method was used to select independent variables for inclusion in the final model (Table 3).

Table 3. Results of multiple linear regression analyses for typical dysfluencies.

\begin{tabular}{lccccc}
\hline Variables & $\beta$ & Standard Error & $\mathrm{t}$ & $95 \% \mathrm{Cl}(\beta)$ & - \\
\hline Constant & 7.38 & 1.56 & - & - & $\mathrm{p}$ \\
Disease duration & -0.31 & 0.14 & -2.13 & -0.61 to -0.01 & 0.042 \\
Other variables: not selected & & & & & \\
\hline
\end{tabular}


Table 4. Results of multiple linear regression analyses for atypical dysfluencies.

\begin{tabular}{lccccc}
\hline Variables & $\beta$ & Standard Error & $\mathrm{t}$ & $95 \% \mathrm{Cl}(\beta)$ & - \\
\hline Constant & 43.24 & 19.45 & - & - & - \\
MMSE & -2.04 & 0.71 & -2.87 & -3.49 to -0.58 & 0.008 \\
Age & 0.31 & 0.14 & 2.24 & 0.03 to 0.59 & 0.034
\end{tabular}

Among the variables studied, the most relevant for typical dysfluency was disease duration: the longer the disease duration, the fewer the number of typical dysfluencies found.

Multiple linear regression analysis was performed to check which variables had the greatest influence on atypical dysfluencies (dependent variable). Age, gender, schooling, disease duration, score on the Hoehn and Yahr scale and score on the MMSE were preselected as independent variables. The step-wise forward method was used to select independent variables for inclusion in the final model (Table 4).

Among the variables studied, the most relevant for atypical dysfluency were MMSE and age: the lower the MMSE score, the greater the number of atypical dysfluencies; and the higher the age, the greater the number of atypical dysfluencies.

\section{DISCUSSION}

The most important findings of this study were that PD subjects had a significantly higher number of speech dysfluencies overall compared to control subjects. Moreover, the analysis of number of typical and atypical dysfluencies revealed an influence from the variables cognitive status, age and disease duration. All subjects in the PDG were dysarthric.

On characterising the overall number of dysfluencies, i.e., the sum of both typical and atypical dysfluencies, it was found that the total number of dysfluencies presented by the PDG was significantly higher than the number observed in the CG. The difference between the groups was attributed mainly to the number of atypical dysfluencies and not to typical dysfluencies.

Based on this data, it is clear that typical dysfluencies, as described previously, are dysfluencies which can be present in the speech of any speaker in the absence of fluency changes characterizing stuttering. As shown by the results, the number of typical dysfluencies presented by the groups was very similar, where the PDG had higher mean word repetitions (up to two-fold higher) and segment repetitions. This finding may possibly be explained by the presence of the repetitive phenomena in the speech of the PD patients.

The age of the subjects studied may also have contributed to the number of typical dysfluencies found, since aging is associated with increased hesitations and pauses in speech, with interjection tending to be the most common typical dysfluency ${ }^{11}$, a fact corroborated in the present study.

The data observed in this study revealed a predominance of atypical dysfluencies in the speech of the PD patients. In addition to palilalia, a condition extensively described in the literature, long pauses, blocks and prolongation were also found to be associated with the disease in the present study. These symptoms have been reported by several other studies $^{8,9}$, along with revisions and interjections ${ }^{8,18,19}$.

It is noteworthy to point out that all the patients in the present study were in the on phase of their medication during assessment. However, a number of studies in the literature have addressed the issues of use of medications for movement improvement in PD and the fluency sequelae induced, although no consensus has been reached among studies on motor production of speech, with some showing improvements $^{20}$, and others deterioration ${ }^{6,8}$ in the on phase.

Concerning speech rate, another aspect of fluency analyzed, the CG was found to be significantly faster than the PDG. The mean spontaneous speech rates found in the present study however, proved higher than those found in an earlier study ${ }^{21}$ of patients with different types of dysarthria. In this case, the dysarthria could be a factor explaining this difference in rates. The structures of the basal ganglia are related with the function of initiating movements, and the speech rate in patients with hypokinetic dysarthria can be accelerated or slowed. In the cases of slowed rates, this reduction in speed may be accompanied by bursts of accelerated speech ${ }^{22,23,24}$. While patients with more severe symptoms display abnormally slow or fast rates, patients with mild PD have relatively normal speech rates ${ }^{25}$. Comparing the two groups in the present study showed a lower speech rate in the $\mathrm{PD}$ than in the CG. Thus, it appears that the presence of episodes of accelerated speech rate, characterized as "speech bursts" in subjects with PD, together with words and syllable repetitions - palilalia, do not translate to a higher speech rate when this is calculated based on words or syllables per minute and compared to healthy subjects without neurological problems. Other notable factors that may hamper the articulation of patients and consequently slow speech rates include difficulty initiating the movements needed for speech and muscle rigidity, although the absence of severe patients in the current casuistic should also be considered. 
Among the variables studied, the most relevant for typical dysfluencies was disease duration (Table 3).

It was found that the longer the disease duration, the fewer the number of typical dysfluencies observed. This may be explained by the fact that as the disease evolves and clinical condition deteriorates there is a predominance of atypical dysfluencies in the speech of PD patients, with typical dysfluencies becoming less evident.

With regard to atypical dysfluencies, the most relevant variables were performance on the MMSE and age, since the lower the MMSE score and the higher the age, the greater the number of atypical dysfluencies in speech.

In fact, aging can also lead to greater typical dysfluencies in the speech of healthy subjects ${ }^{11,26}$. while atypical dysfluencies are less frequently observed. More specifically, in the case of PD patients, older age was associated with more atypical dysfluencies, strongly suggesting the occurrence of this problem in the disease with greater likelihood of occurrence in older patients.

One of the criteria for inclusion of subjects in the study was that score on the MMSE, adjusted for schooling, had to lie within normal limits. Thus, subjects scoring less than normative values were excluded from the study at the outset. The association between lower score on the MMSE and a higher number of atypical dysfluencies suggests that low schooling may have interfered in the results. Schooling ranged from four to fifteen years of formal education where MMSE cut-off scores are applied to participants based on level of schooling, with lower cut-offs for individuals with fewer years of schooling. Level of schooling of the subject can impact both the organizing of discourse ${ }^{27}$, and oral production $^{12}$, contributing to dysfluencies ${ }^{28}$. The theory of interaction between worse performance on the MMSE and lower level of schooling of the subjects also involves the question of impact of schooling on the course of diseases. There is a growing body of evidence suggesting that greater schooling delays clinical onset and that a higher level of schooling exerts a protective effect against neurological diseases ${ }^{29}$.

In conclusion, overall, the PD patients had a higher number of speech dysfluencies with an elevated number of atypical dysfluencies. Speech rate was slower in the PDG. The variables cognitive status (MMSE), disease duration and age had an influence on the occurrence of dysfluencies and consequently on speech problems in patients with PD.

\section{Acknowledgments}

We would like to thank Professor Henrique Ballalai Ferraz the opportunity to do this research with patients that are assisted at the Sector for Motor Disorders of the Department of Neurology of the Universidade Federal de São Paulo.

\section{References}

1. Darley FL, Aronson A, Brown JR. Motor speech disorders. Philadelphia, London, Toronto: Saunders; 1975.

2. Culatta R, Leeper LH. Disfluency insát always stuttering. J Speech Hear Disord 1988;53:483-488

3. Alm P. Stuttering and the basal ganglia circuits: a critical review of possible relations. J Commun Disord 2004;37:325-369.

4. Koller WC. Disfluency (stuttering) in extrapyramidal disease. Arch Neurol 1983;40:175-177.

5. Benke T, Hohenstein C, Poewe W, Butterworth B. Repetitive speech in Parkinson's disease. J Neurol Neurosurg Psychiatry 2000;69:319-325

6. Louis ED, Wineld L, Fahn S, Ford B. Speech dysfluency exacerbated by levodopa in Parkinson's disease. Mov Disord 2001;16:562-565.

7. Goberman A, Blomgren M, Metzger E. Characteristics of speech disfluency in Parkinson disease. J Neuroling 2010;23:470-478.

8. Shin HY, Lee WY, Suh MK. Palilalia as a symptom of levodopa-induced oromotor hyperkinesia in Parkinson's disease. Parkinsonism and Related Disorders 2007:119

9. Souques A. Palilalia. Rev Neurol (Paris) 1908;16:340-343.

10. Van Borsel J, Lierdea KV, Cauwenbergea PV, Guldemontb I, Orshovenc MV. Severe acquired stuttering following injury of the left supplementary motor region: a case report. J Fluency Disord 1998;23:49-58.

11. Andrade CRF, Martins VO. Variação da fluência da fala em idosos. Pró-Fono 2010;22:13-18.

12. Cera M, Ortiz KZ, Bertolucci PHF, Minett TSC. Speech and orofacial apraxias in Alzheimer's disease. Int Psychogeriatr 2013;25:1679-1685.
13. Brucki SMD, Nitrini R, Caramelli P, Bertolucci PHF, Okamoto $\mid H$. Sugestões para o uso do Mini-Exame do Estado Mental no Brasil. Arq Neuropsiquiatr 2003;61:777-781.

14. Hoehn MM, Yahr MD. Parkinsonism: onset, progression and mortality. Neurology 1967;17:427-442.

15. Riley GD. Stuttering severity instrument for children and adults-SSI. Austin: Pro-ed, 1994.

16. Le Boeuf, C. Raconte - 55 historiettes en images. Paris: L'Ecole, 1976.

17. Andrade CRF. Fluência. In: Andrade CRF, Lopes DMB, Fernandes FDM, Wertzner E (Eds). ABFW - teste de linguagem infantil nas áreas de fonologia, vocabulário, fluência e pragmática. $2^{\text {nd }}$ ed. Carapicuiba: Pró-Fono, H.F 2004:51-81.

18. Van Borsel J, Coryn CBM, Paemeleire F, Vandemaele P. Acoustic features of palilalia: a case study. Brain Lang 2007;10:90-96.

19. Van Borsel J, Taillieu C. Neurogenic stuttering versus developmental stuttering: an observer judgement study. J Commun Disord 2001;34:385-395

20. Benke T, Butterworth B. Palilalia and repetitive speech: two case studies. Brain Lang 2001;78:62-81.

21. Oliveira CR, Ortiz KZ, Vieira MM. Disartria: estudo da velocidade de fala. Pró-Fono 2004;16:39-48.

22. Scott S, Caird FI, Willians Bo. Communication in Parkinson's disease. London: Croom Helm, 1985.

23. Tjaden K. A preliminary study of factors influencing perception of articulatory rate in Parkinson's disease. J Speech Lang Hear Res 2000;43:997-1010. 
24. Yorkston KM, Beukelman DR, Strand EA, Bell KR. Management of motor speech disorders in children and adults. $2^{\text {nd }}$ ed. Austin, TX: Pro-Ed., 2000.

25. Metter EJ, Hanson WR. Clinical and acoustical variability in hypokinetic dysarthria. J Commun Disord 1986;19:347-366.

26. Leeper LH, Culatta R. Speech fluency: effect of age, gender and context. Folia Phoniatr Logop 1995;47:1-14

27. De Lira J, Ortiz KZ, Campanha AC, Bertolucci PHF, Minett TSC. Microlinguistic aspects of the oral narrative in patients with Alzheimer's disease. Int Psychogeriatr 2011;23:404-412.

28. Kuoppamaki M, Rothwell JC, Brown RG, Quinn N, Bhatia KP, Jahanshahi M. Parkinsonism following bilateral lesions of the globus pallidus: performance on a variety of motor tasks shows similarities with Parkinson's disease. J Neurol Neurosurg Psychiatry 2005;76:482-490.

29. Parente MAMP, Scherer LC, Zimmermann N, Fonseca RP. Evidências do papel da escolaridade na organização cerebral. Rev Neuropsicol Latinoamericana 2009;1:72-79. 